www.periodicos.unimontes.br/index.php/caminhosdahistoria

\title{
OS CONFLITOS ENTRE A LEI IGUALITÁRIA DE HERANÇA E AS NORMAS COSTUMEIRAS EM GUARAPIRANGA (MG) - 1715 A 1820
}

Débora Cristina Alves ${ }^{1}$

Resumo: O presente trabalho tem como intuito analisar as diferentes estratégias e métodos empregados pelas famílias de elite na região de Guarapiranga para manterem e perpetuarem seus bens materiais e imateriais. Por intermédio de inventários post-mortem, processos matrimoniais, cartas patentes do Arquivo Histórico Ultramarino e documentos do Arquivo da Torre do Tombo, a pesquisa se ateve a analisar uma família em específico que residiu na região, os Pinto Alves, no período entre 1715 a 1820, a fim de examinar os mecanismos de ascensão e preservação das posses ao longo de gerações. Para tanto, observamos as leis igualitárias de herança e sucessão definidas tanto para Portugal quanto para o Brasil e as leis costumeiras empregadas pelos indivíduos e suas famílias para que os bens, principalmente posses de terras, não fossem dissipados ao longo das gerações pela divisão do espólio. Práticas como "vendas fantásticas", venda de meação e de posses a um único herdeiro foram alguns dos métodos utilizados para burlar as leis portuguesas que impuseram a igualdade do patrimônio entre os herdeiros.

Palavras-chave: Herança; Sucessão, Normas Costumeiras; Ascensão Social; Preservação do Patrimônio.

Abstract: The present work aims to analyze the different strategies and methods employed by elite families in the Guarapiranga region to maintain and perpetuate their material and immaterial goods. Through post-mortem inventories, matrimonial proceedings, patent letters from the Overseas Historical Archiv e and documents of the Torre do Tombo Archive, the research focused on analyzing a specific Family that live in the region, the Pinto Alves, in the period between 1715 and 1820, in order to examine the mechanisms of ascension and preservation of possessions over generations. To this end, we observe the egalitarian laws of inheritance and defined for both Portugal and Brazil, ant the costumoray laws employed by individuals and their families so that property, especially land tenures, have not been dispelled over the generations by the Division of the estate. Practices such as "fantastic sales", sale of meation and possessions to as ingle heir some of the methods used to circumvent portuguese laws that imposed the equality of property among the heirs.

Keywords: Inheritance; Succession, Customary Norms; Social Ascension; Heritage Preservation.

\section{Introdução}

Localizada ao sul de Mariana, a freguesia de Guarapiranga "foi um dos primeiros povoados a surgir em meio à mata virgem e densa dos sertões da então capitania do Rio de

\footnotetext{
${ }^{1}$ Doutora em História pela Universidade Federal de Juiz de Fora. Professora Substituta de História no Colégio Aplicação João XXIII. E-mail: dediliber@yahoo.com.br. ORCID: https://orcid.org/0000-0003-1949-0428.
} 
Janeiro, quando as Minas Gerais ainda não existiam juridicamente como capitania autônoma" (LOPES, 2012). No Códice Matoso encontram-se os primeiros registros da chegada de homens brancos na região, em 1691, quando uma bandeira liderada por Francisco Rodrigues Salgado e Antônio Pires Rodovalho encontraram ouro à beira do rio. Nas margens do córrego das Almas se assentara o novo arraial denominado Guarapiranga, graças aos pássaros pequenos e vermelhos que habitaram o lugar (guará $=$ vermelho, piranga $=$ pequeno) (FIGUEIREDO; CAMPOS, 2012, p. 30).

O incentivo do ouro e de outras produções associadas à localização geográfica da freguesia, entre a urbe e o sertão, converteu a região de Piranga em porta de entrada para incursões de conquista e povoamento acelerado, transformando-o em um dos principais núcleos auríferos (ANDRADE, 2014).

A freguesia, ao final do século XVIII e início do XIX, possuía uma população relativamente volumosa para o período, com mais de 10.000 habitantes (CARRARA, 2007, P. 37-38), o que fez de Piranga uma região economicamente dinâmica e relativamente diversificada $^{2}$. Sustentáculo de Mariana e Ouro Preto, a freguesia abastecia essas cidades com aguardente e outros produtos agrícolas menos expressivos e oferecia uma alternativa de imigração constante.

Para compreender os processos de herança e sucessão na região analisamos para o período os inventários post-mortem, processos matrimoniais, testamentos, documentos do Arquivo Histórico Ultramarino e do Arquivo da Torre do Tombo. A princípio empregamos alguns dos métodos utilizados na reconstituição de paróquias (AMORIM; DURÃES; FERREIRA, 2003), que por intermédio de indicações nominativas, definiu-se como unidade de análise o indivíduo e seus encadeamentos genealógicos, permitindo iluminar os ciclos familiares e servindo, segundo Robert Rowland (1997), não apenas a fins de análise demográfica, mas também de história social.

O período selecionado foi assim delimitado em virtude dos seguintes fatores: o primeiro inventário específico sobre a região de Guarapiranga localizado nos arquivos foi do ano de 1715, conduzindo-nos, assim, a demarcar a data como início da pesquisa. Por sua vez, 1820 foi determinado como ponto de arremate para que nossa pesquisa não transpusesse as

\footnotetext{
${ }^{2}$ Em fins do século XVIII e nas primeiras décadas do XIX, foram realizadas pelo Padre Lino de Matos, a contagem da população da freguesia de Guarapiranga, em que indicou o crescimento da população livre e a diminuição do hiato entre a população escrava frente a livre e liberta. Em números, de acordo com o pároco, em 1797 habitavam a paróquia 5.124 indivíduos livres e libertos e 5.665 escravizados, já em 1812 o montante de livres e libertos se expandiu para 7.610 e 5.409 cativos. Em 1830, os livres e libertos somavam 7.442 indivíduos e os escravizados 3.521. "Taboa de população da Freguesia de Guarapiranga da região de Mariana, 31 de dezembro de 1797, elaborado por Lino Lopes de Mattos", APM, Casa dos Contos, Cx. 94. In: ANDRADE, 2014, p. 37.
} 
barreiras do período imperial do Brasil, no qual se desenrolaram diferentes mudanças na estrutura social e política do país.

Para tanto, selecionamos entre os indivíduos analisados da região, uma família em específico, os denominados "Pinto Alves", identificados em diferentes gerações para tornar possível a compreensão dos conflitos existentes no período entre as leis de herança e sucessão, vigentes tanto em Portugal e no Brasil, e as normas costumeiras que visavam privilegiar e manter os bens adquiridos entre os partícipes das parentelas. Embora as leis portuguesas e as Ordenações decretassem a igualdade de direitos aos descendentes à herança e tenham tornado o direito à legítima sagrado e inviolável, os indivíduos elaboraram diferentes estratégias para impedir a divisão das posses de terra, mantendo, assim, a sobrevivência econômica do ciclo familiar.

Inseridos em uma ótica de prerrogativas, distinções e hierarquização, características de uma sociedade de Antigo Regime, as famílias prósperas procuraram ascender socialmente, através de concessões de benefícios, casamentos, funções políticas e sociais que lhes puderam conferir destaque social e reconhecimento. Como ressaltou João Fragoso: "pertencer de fato à nobreza da terra significava ter o "consentimento" da sociedade, ser visto por esta como nobre ou, até mesmo, ser reconhecido como membro de um grupo de qualidade superior" (FRAGOSO, 2001, P. 58).

Desenvolver alianças profícuas por intermédio dos matrimônios, redes sociais, políticas e econômicas entre os principais da região e possuir ofícios e cargos vantajosos igualmente possibilitaram aos colonos e suas famílias ascensão social e poder, elementos imprescindíveis em uma sociedade notadamente hierarquizada e excludente.

Assim, com a análise apurada do processo sucessório de cada um destes indivíduos será possível compreender detalhadamente parte da rede de artifícios, negociações, estratégias e acordos que a população de Guarapiranga no século XVIII e início do XIX empregou para manter, ampliar e evitar a dissolução do patrimônio material e imaterial obtido com grande esforço ao longo de suas trajetórias.

\section{Leis de Herança e Sucessão}

Acompanhada à crescente produção econômica, a freguesia de Guarapiranga, assim como outras tantas regiões coloniais, recebeu uma expoente imigração de portugueses provenientes principalmente do Norte de Portugal. Dentre os 318 inventários post-mortem catalogados, dentre 293 homens, 133 foram provenientes do reino. 
Diversamente do que afirmou Caroline Brettell (1991), esses portugueses não retornaram, mas permaneceram nas Minas e constituíram família, patrimônio e honrarias. Preservar os bens, como terras e escravizados e garantir os benefícios simbólicos adquiridos por status, benesses, mercês e ofícios foram determinantes para que esses indivíduos vivessem a chamada lei da nobreza ${ }^{3}$ e reproduzissem, portanto, o costume aristocrático português. Para tanto, diferentes foram as estratégias empregadas para manterem em família os ganhos sociais, econômicos e políticos angariados.

Por partilha entendemos o montante de bens e recursos deixados pelo falecido, o qual, pela tradição do direito sucessório português e da sucessão testamentária (codificados nas Ordenações Filipinas, Livro $\mathrm{IV}^{4}$ ), requereu ser segmentada igualitariamente entre os herdeiros legítimos (independentemente de idade ou sexo). Por sucessão entendemos os resultados concretos (e potencialmente desiguais e conflituosos) da transmissão patrimonial, modificados pela possibilidade legal de disposição testamentária da terça, pela instituição do dote e por transações e rearranjos compensatórios entre os herdeiros.

Em áreas marcadas pela expansão mineral e agrícola, as regras de transmissão de herança foram estratégicas para a reprodução e manutenção das unidades domésticas. Com proles numerosas, as famílias, em sua maioria, se preocuparam em manter a distinção do "nome", evitando a todo custo a eventual fragmentação do patrimônio familiar. Foi preciso, contudo, instituir estratégias precisas para evitar uma fragmentação excessiva por intermédio de regras preferencias de acesso à terra por parte de certos membros do grupo familiar ou optar pela consanguinidade nas alianças matrimoniais (MOURA, 1978).

Embora o morgadio como instituição não tenha se enraizado na colônia ${ }^{5}$, diferentes foram os métodos empregados pelos sujeitos para a preservação dos bens simbólicos e indivisíveis. Em seu recente trabalho, Carla Almeida encontrou para homens listados entre os mais ricos de Minas Gerais no século XVIII as chamadas "vendas fantásticas", em que os indivíduos "realizariam transações fictícias visando exclusivamente a manutenção do patrimônio e não a venda efetiva dos bens" (ALMEIDA, 2015). De acordo com a autora foi possível afirmar que:

\footnotetext{
3 O viver ao estilo e lei da nobreza, que tinha como características fundamentais: honra, prestígio, reconhecimento público, insígnias, precedências e aparato nos exercícios de suas funções. In: MAGALHÃES, 1988.

${ }^{4}$ Ordenações Filipinas, Livro IV. Disponível em: http://www1.ci.uc.pt/ihti/proj/filipinas/14ind.htm. Acesso em: 17 de julho de 2018.

${ }^{5}$ Alguns trabalhos abordam a existência de morgados específicos no Brasil, como o "Morgadio da Casa da Torre dos Garcia de Ávila", instituído no período em que Tomé de Souza chegou à Bahia em 1549, e manteve-se por sucessivas gerações nesta família, até a extinção dos morgadios no Brasil (lei n 57 de outubro de 1835". In: CALDEIRA, 2007.
} 
[..] guardadas as devidas diferenças da condição social e da dimensão das posses destes homens das Minas, buscava-se com as vendas fantásticas algo que no Reino era parte da tradição das famílias nobres, o estabelecimento dos vínculos para a preservação dos bens que garantissem a perpetuação da casa (ALMEIDA, 2015, p. 6).

Na paróquia em análise, encontramos no inventário de Domingos Barbosa Pillar, de 1761, uma transação que foi efetuada pelo inventariado, descrita como "venda fantástica"6. De acordo com os autos, a princípio, Domingos Barbosa vendeu a maior parte de seus bens a Francisco Fernandes de Sá Miguel, em 28 de setembro de 1761, um dia antes do seu falecimento, no valor total de 8 mil cruzados (3:200\$000 réis - 900,140 libras) que deveria ser pago em 16 anos no valor anual de $200 \$ 000$ réis $(56,258 \text { libras })^{7}$. O genro de Domingos Barbosa relatou no inventário que a venda fora engendrada para que alguns dos bens do inventariado não se destituíssem a fim de sanar algumas dívidas:

Diz Joaquim José de Sousa por cabeça de sua mulher herdeira de Domingos Barbosa Pillar e sua mulher Margarida Antunes e desta o benefício de inventario que falecendo o pai comum senão descreveu no inventário deste uma datas de terras e águas minerais no veio do córrego de água, das casas da fazenda em razão de uma fantástica venda armada a Francisco Fonseca São Miguel e procedendo-se no inventário materno senão deu valor algum as ditas datas de terras e águas minerais como para ser julgada nela a dita venda se há de proceder a partilha da legitima paterna para esta [?] o suplente nas mesmas terras e águas minerais do veio do dito córrego no valor de 12 mil réis requer a vossa mercê seja servido mandar se tome termo de licitação e se passe em o dito para ser intimado ao segundo marido e herdeiros esta licitação e não se pondo estes na partilha a que se proceder da legítima paterna se adjudique ao suplente as ditas terras e águas minerais na dita quantia ${ }^{8}$.

Os bens "vendidos" a Francisco de Sá Miguel entraram como crédito na partilha, constituindo, com mais três escravizados, um casaco e uma espora velha, o total de bens que Domingos possuiu para o quinhão. O monte-mor foi avaliado, assim, em 3:392\$900 réis (954,402 libras), e a cada herdeiro o legado foi de 424\$112 réis (119,300 libras). Evitando um possível leilão de seus bens em praça pública, Domingos Barbosa realizou uma suposta venda de quase todo seu patrimônio a Francisco de Sá Miguel, para que, no momento da elaboração do seu inventário, as dívidas adquiridas ao longo dos anos estivessem relegadas ao pagamento anual de apenas $200 \$ 000$ réis $(56,258$ libras) propostos na negociação, conservando entre os

\footnotetext{
${ }^{6}$ Embora não tenha sido possível diagnosticar nos 318 inventários catalogados quantos apresentaram a estratégia das vendas fantásticas, conseguimos identificar entre as quatro famílias analisadas e pré-selecionadas, que o método de supostamente vender os bens antes da partilha, para que o patrimônio não fosse de todo fragmentado, foi prática usual. Conquanto, não apareça nos autos dos inventários e testamentos com o nome de "venda fantástica", o processo se constituiu o mesmo.

${ }^{7}$ Inventário post-mortem de Domingos Barbosa Pillar, ACSM, $1^{\circ}$ ofício, códice 28, auto 709, 1761.

${ }^{8}$ Inventário post-mortem de Domingos Barbosa Pillar, ACSM, $1^{\circ}$ ofício, códice 28, auto 709, 1761.
} 
herdeiros os principais bens familiares, em especial as terras e as lavras minerais. As denominadas vendas fantásticas, portanto, auferiram ao inventariado a possibilidade de manter os principais bens familiares nas mãos dos descendentes, evitando, assim, extensos danos ao patrimônio.

Com o segundo matrimônio da viúva de Domingos Barbosa e o falecimento da mesma, os filhos e os genros entraram em litígio com o consorte, exigindo a partilha correta dos bens dos progenitores, descrevendo em detalhes os bens adquiridos com a suposta venda fantástica a Francisco de Sá Miguel. Nesse ínterim, o patrimônio "vendido" entrou novamente no parecer dos bens avaliados, assim como os bens adquiridos após o segundo matrimônio. Ademais, uma nova partilha foi contabilizada, conferindo a soma a cada herdeiro de $887 \$ 090$ réis $(249,533 \text { libras })^{9}$ em 1791, 30 anos após o início do processo.

Possivelmente, como assinalado, se a venda fantástica a Francisco de Sá, das terras e águas minerais, alguns escravizados e uma casa de vivenda não ocorresse, tais recursos estariam integrados no pecúlio a ser partilhado e empregado no pagamento das dívidas, ocasionando prejuízos sobressalentes à família e à sua sobrevivência. Ao usufruir, portanto, da estratégia da venda, Domingos Barbosa possibilitou aos descendentes manter em família os principais patrimônios que garantiram a manutenção e a sobrevivência de todos, além de ter preservado o status e privilégios aos sucessores, assegurando promissores matrimônios e aquisição de ofícios e benefícios.

Conjunturas como as enfrentadas pela família de Domingos Barbosa foram comuns entre a maioria dos indivíduos de grande e média fortuna na paróquia, que procuraram delimitar estratégias plausíveis no intuito de evitar dissoluções críticas no patrimônio familiar. Conquanto não tenhamos acesso a todos os inventários que empregaram desse artifício, observamos, ao longo da análise, outras circunstâncias como as descritas, de vendas fantásticas e outros métodos nos processos, que visaram burlar a divisão igualitária da herança e o fracionamento dos bens imóveis.

Com base nessas disposições e nos dados encontrados nos inventários post-mortem do período, dos quais os indivíduos com posses de terras em extensão e riquezas instituíram diferentes mecanismos para garantir a preservação do patrimônio evitando a fragmentação dos bens entre os herdeiros, propomo-nos relacionar as informações já catalogadas com as legislações e os documentos do período que forneçam dados sobre os diferentes recursos operados pelas famílias nos processos de sucessão e herança em Portugal e que foram

\footnotetext{
${ }^{9}$ Inventário post-mortem de Domingos Barbosa Pillar, ACSM, $1^{\text {o }}$ ofício, códice 28, auto 709, 1761.
} 
reproduzidos na colônia no tempo-espaço indicados, definido os métodos executados por esta elite para burlar as leis impostas.

Para compreender tais procedimentos nos baseamos em autores como Margarida Durães, Nuno Gonçalo Monteiro, entre outros, que indicaram em suas investigações algumas das estratégias e métodos empregados pelas famílias portuguesas nos processos de herança e sucessão. De acordo com Nuno Monteiro, em Portugal, ao longo do século XVI, mas sobretudo nos dois ulteriores, o modelo reprodutivo vincular "não se traduzia apenas na fundação de vínculos (morgados), mas ainda no encaminhamento da grande parte das filhas e da maioria dos filhos secundogênitos para as carreiras eclesiásticas” (MONTEIRO, 1993, p. 45).

A reprodução alargada da "casa", os modelos de distinção estabelecidos entre os sucessores e os outros filhos nos círculos de nobreza e em outros grupos portugueses analisados por Nuno Monteiro e outros autores, nos forneceram elementos primordiais para compreender de que forma os processos de partilha e sucessão se evidenciaram entre as famílias coloniais. Para compreender o conceito de "casa" foi preciso identificar sua distinção em relação à "linhagem", como instituiu Nuno Monteiro em um dos seus trabalhos, no qual descreveu que:

[...] quase todos os fidalgos portugueses dos séculos XVII e XVIII nasciam numa determinada casa, identificada pela posse de certos bens vinculados, de uma comenda, de um senhorio, de um ofício palatino e/ou, por fim, de um título nobiliárquico. Muitas vezes, sucessivamente de tudo isso, embora, quando o possuía, fosse sempre o título nobiliárquico o que dava nome a uma casa. A distinção entre a linhagem (de origem necessariamente remota) e casa (de fundação mais recente) é fundamental para a compreensão das práticas matrimoniais da aristocracia portuguesa (MONTEIRO, 1993, p. 45).

Embora o direito de primogenitura e os morgados não tenham prevalecido de forma rígida na colônia brasileira, com poucas famílias consideradas realmente como nobres (a sua quase totalidade nunca deteve prerrogativas como a isenção do pagamento de impostos e a total autonomia jurisdicional), esses indivíduos se situaram entre a vigência de um direito sucessório igualitário e de uma cultura aristocrática, já que possuíam bens indivisíveis e valiosos (PEDROAZA, 2010, p. 142).

E ainda que haja imensas dificuldades em enquadrar essas famílias segundo critérios clássicos da aristocracia europeia, estas procuraram vivenciar os padrões instituídos aos pertencentes a determinada "casa", cumprindo uma disciplina familiar de condutas e preceitos, tais como: a aliança matrimonial com outras "casas" (casa camponesa e não no 
sentido aristocrático) ${ }^{10}$; concessão de dotes volumosos; reprodução do "renome" da casa por intermédio dos casamentos femininos; casar e dar descendência e filhos que seguiram a carreira eclesiástica ou se mantiveram celibatários (MONTEIRO, 1993). Tais princípios foram trilhados pela maioria das famílias ricas e privilegiadas no período colonial e pelas parentelas analisadas para a região de Guarapiranga.

Essas análises, mais do que nos ajudar a entender a origem, a evolução e as características das instituições jurídicas, possibilitaram um conhecimento da sociedade, investigando a repartição, devolução e acesso dos indivíduos ao patrimônio e às formas de utilização das instituições e leis ao seu favor. Nas palavras de Durães: “é o conhecimento dos princípios básicos que regulam a organização do agregado familiar e da sociedade, que está intrínseco a toda a análise histórica social" (DURÃES, 2001, p. 177).

Por consequência, a investigação de processos de herança e sucessão, mais do que análise de leis e jurisdições, forneceu dados imprescindíveis para a concepção da sociedade portuguesa e suas semelhantes ou diferentes interpretações aplicadas nas possessões ultramarinas, especificamente na colônia brasileira e em uma comunidade próxima ao núcleo minerador de Mariana - Guarapiranga.

\section{Os Pinto Alves e seu legado patrimonial}

João Pinto Alves ${ }^{11}$, o primeiro indivíduo localizado para a família em análise, em $1725^{12}$, consorciou-se com Dona Mariana Correia de Oliveira, proveniente de família do Rio de Janeiro, mas há longos anos residente na região de Mariana. Mariana Correa não foi uma mulher comum, sua condição financeira e de privilégios concedeu-lhe o título de importante pretendente nas Minas. Irmã de Manoel de Oliveira, outro minerador e também incluso na lista de $1756^{13}$ entre os homens mais ricos da região, Dona Mariana carregava uma coligação poderosa e vantajosa de redes familiares, alianças sociais, econômicas e políticas que foram transferidos ao cônjuge "arranjado" pela parentela.

\footnotetext{
10 "Casava quem tinha ou quem podia entrar numa casa. As sucessões femininas das casas dos Grandes criavam, assim, oportunidades para os secundogênitos poderem escolher o estado do matrimônio. Muitas vezes, eram os secundogênitos das próprias casas, ou seja, os tios, que se procuravam para o efeito". In: MONTEIRO, 1993, p. 54. Os destinos dos filhos e filhas eram definidos estrategicamente para a reprodução das casas, cada um tinha seu papel na perpetuação da família.

${ }^{11}$ Como descrito anteriormente, outros estudos analisaram esse indivíduo e suas nuances. Ver: ALMEIDA, 2006; ALMEIDA, 2015.

${ }_{12}$ ACSM, Inventário post-mortem de Mariana Correia de Oliveira, $1^{\text {o }}$ ofício, códice 46, auto 1050, 1748.

${ }^{13}$ Lista dos Homens mais ricos das Minas. ALMEIDA, 2010.
} 
Embora sem informações contundentes sobre sua família, sabemos que eram provenientes do Rio de Janeiro e que se deslocaram para as Minas, anos antes do seu enlace com João Pinto ${ }^{14}$. Inseridos, fixados e enriquecidos, a família de Mariana representava para o lusitano a possibilidade de enobrecimento, desenvolvimento e enraizamento. Por sua vez, para a parentela, o consórcio com o português - que dispôs de posse e prestígio previamente ao consórcio - os distanciava de possível miscigenação e popularização.

Do enlace entre Mariana e João Pinto foram gerados 11 filhos ${ }^{15}$ que seguiram os parâmetros impostos às "casas" (camponesas), perseguindo padrões comportamentais previamente estabelecidos para as famílias, nos quais cada indivíduo, dentro da lógica, reproduzia um costume, que se alterava entre: casar com indivíduos que conduziram poder e privilégios à família, manter-se celibatário no lar ou seguir carreira eclesiástica (MONTEIRO, 1993).

Por esse viés, Francisca Pinta, a primogênita do casal, consorciou-se com Antônio Duarte, um poderoso lusitano morador das Minas, em $1740^{16}$. Outros dois filhos, Antônio de Oliveira e João de Oliveira estudaram em Coimbra, retornando o primeiro à região para exercer a função clerical; os descendentes Manoel de Oliveira e Fernando de Oliveira seguiram carreira eclesiástica em seminários no Rio de Janeiro; as filhas Jerônima de Oliveira, Sebastiana de Oliveira e Ana de Oliveira tornaram-se freiras; José de Oliveira e Angélica Eufrásia permaneceram nos arredores do domicílio paterno, e Maria de Oliveira igualmente se casou, permanecendo na região ${ }^{17}$. Embora não tenhamos acesso ao destino final de vários destes indivíduos, sabemos que se inseriram no rol de famílias importantes e nobilitantes em terras lusitanas e coloniais, adquirindo e perpetuando vultosas benesses e privilégios.

João Pinto Alves não foi um lusitano comum. Como importante minerador nas Minas e detentor de muitas posses, obteve o cargo de vereador na Câmara de Mariana (CHAVES; PIRES, MAGALHÃES, 2008), auferindo, com facilidade, a mercê do Rei para se deslocar para o Reino no ano de $1735^{18}$, quando foi, com a esposa e quatro filhos, solucionar pendências após o falecimento dos pais, permanecendo por um período em terras portuguesas

\footnotetext{
${ }^{14}$ ACSM, Inventário post-mortem de Mariana Correia de Oliveira, $1^{\circ}$ ofício, códice 46, auto 1050, 1748.

${ }^{15}$ Francisca Pinta de Oliveira, João de Oliveira Pinto, Antônio de Oliveira Pinto, Maria de Oliveira, Manoel de Oliveira Pinto, Fernando de Oliveira Pinto, Jerônima de Oliveira Pinto, Sebastiana de Oliveira Pinto, Anna de Oliveira Pinto, José de Oliveira e Angélica Thereza de Oliveira. In: ACSM, Inventário post-mortem de Mariana Correia de Oliveira, $1^{\circ}$ ofício, códice 46, auto 1050, 1748.

${ }^{16}$ Arquivo Eclesiástico da Arquidiocese de Mariana, processo matrimonial $\mathrm{n}^{\circ}$ 433, armário 01, pasta 44. In: ALMEIDA, 2010, p. 176 e 177.

${ }^{17}$ ACSM, Inventário post-mortem de Mariana Correia de Oliveira, $1^{\text {o }}$ ofício, códice 46, auto 1050, 1748.

${ }^{18}$ AHU, cx. 30, doc. 36 de 02/12/1735.
} 
e regressando ao Ultramar. Posteriormente, o lusitano logrou o Hábito da Ordem de Cristo em $1749^{19}$, ampliando seu prestígio e relevância na localidade em que residia. Com todos esses cabedais e com o título de Capitão ${ }^{20}$ de alguma tropa de Ordenança ou Milícia na região o português conquistou diversos bens a si e aos familiares, avaliados, em 1748, em 32:164\$500 réis (9.047,679 libras), dos quais, ao fim do processo, coube a cada herdeiro o montante de $900 \$ 547$ réis $(253,318 \text { libras })^{21}$.

De acordo com os autos, a família do português possuiu dívidas com alguns indivíduos da região e gastos com o funeral de Mariana Correa, o que reduziu o montante do patrimônio para 19:812\$048 réis $(5.573,009$ libras). Os débitos principais inseridos no inventário foram com o Capitão Francisco Ribeiro Filgueira de 1:829\$656 réis $(514,671$ libras) e com o genro Antônio Duarte de 7:738\$500 réis (2.176,793 libras) e o funeral da esposa que somou $313 \$ 500$ réis $(88,185 \text { libras })^{22}$.

Ao que sabemos, João Pinto e o genro foram sócios na lavra de minerar no Morro da Passagem e em alguns escravizados, o que, de fato, gerou as respectivas dívidas ou se constituíram como estratégia para diminuição do montante do patrimônio para divisão igualitária dos bens e abatimento das demais dívidas. No processo constou, portanto, que o casal liquidou o débito com o genro Antônio, restituindo-lhe onze escravizados e o valor de 5:977\$500 réis (1.681,434 libras) referentes à sua cota na lavra de minerar ${ }^{23}$.

Sem contendas ou maiores complicações descritas no inventário, em 1750, a partilha foi realizada, constando nos autos que o filho, Pe. Antônio Pinto de Oliveira, auferira a legítima materna no embolso do patrimônio doado pelo genitor para seu sacerdócio ${ }^{24}$. Conquanto não disponhamos do inventário de João Pinto, conhecemos pelos dados descritos nos livros de nota que os bens desse português não se limitaram ao que foi identificado no inventário da esposa Mariana, encontrando-se reduzido na inventariação, posto que o arrolamento não expos, a título de exemplo, um sítio em Pirapetinga, supostamente vendido em 1731, mas reaparecendo em duas transações em $1773^{25}$.

Esses sujeitos negociavam, por vezes, fragmentos da porção de terra que possuíam, fazendo sociedades com um ou mais indivíduos, como na propriedade Pirapetinga de João

\footnotetext{
${ }^{19}$ ANTT, Habilitação da Ordem de Cristo, Letra J, Maço 92, número 49, 1749.

${ }^{20}$ ACSM, Inventário post-mortem de Mariana Correia de Oliveira, $1^{\circ}$ ofício, códice 46, auto 1050, 1748.

${ }^{21}$ Ibidem.

${ }^{22}$ ACSM, Inventário post-mortem de Mariana Correia de Oliveira, $1^{\circ}$ ofício, códice 46, auto 1050, 1748.

${ }^{23}$ ACSM, Inventário post-mortem de Mariana Correia de Oliveira, $1^{\circ}$ ofício, códice 46, auto 1050, 1748.

${ }^{24}$ Como descrito anteriormente os filhos que optaram pela vida eclesiástica, receberam dos genitores, um patrimônio, entre terras, escravizados e outros bens, para que obtivessem recursos ao longo de seu sacerdócio.

${ }_{25}$ As vendas foram descritas ao longo do capítulo 2. ACSM, Livro de Notas, 36, $1^{\circ}$ oficio, número 652, 01/09/1731 e ACSM, Livro de Notas 91, $1^{\circ}$ ofício, número 1280, 27/08/1773.
} 
Pinto, que foi comercializada em 1731 a Luís Corrêa e Francisco Machado ${ }^{26}$ (possivelmente parte dela) e renegociada, em $1773^{27}$, a Manoel Correa de Oliveira (seu genro). Dispondo na transação como sócios de João o genro Antônio Duarte e José da Silva e, posteriormente, vendida em 1773 a sua filha Angélica Eufrásia ${ }^{28}$.

Consideramos que as duas últimas transações realizadas por João Pinto em 1773 tiveram como intenção manter as posses sem maiores fragmentações, já que, ao vendê-las, supostamente, à filha Angélica Eufrásia e ao cunhado Manoel de Oliveira, as posses de terras foram removidas do rol de bens inventariados, desobrigando o lusitano a uma divisão igualitária da propriedade entre os herdeiros ou de sua possível comercialização para pagamentos de dívidas.

Assim inferimos, posto que o patrimônio negociado com a filha e o cunhado foram os mesmos, no Morro da Passagem e na Pirapetinga, com valores idênticos de 18:000\$000 réis (5.063,291 libras) pagos ao longo de 23 anos por Manoel Oliveira ${ }^{29}$ e 20 anos para Angélica Eufrásia $^{30}$. Estipulando um valor para o devedor restituí-lo, como o fez com o cunhado - que pagaria $800 \$ 000$ réis $(225,035$ libras) ao ano -, o lusitano inseriu na listagem dos bens aquinhoados unicamente o montante que Manoel deveria liquidar, suspendendo, desta forma, a secessão de suas terras, conservando-as íntegras nas mãos dos herdeiros. Repetidamente, identificamos as denominadas "vendas fantásticas" nos mecanismos empregados pelas famílias no setecentos.

As estratégias de João Pinto foram, ao que parece, bem-sucedidas, conservando as posses de terras e lavras minerais nas mãos dos familiares, em específico do genro Antônio Duarte, que passou a geri-las posteriormente ao falecimento do sogro, mantendo-as em seu poder $^{31}$. Antônio Duarte foi um português, como descrito, proveniente da região de Coimbra, que viera ainda jovem para terras brasileiras, fixando-se nas Minas, e construindo um extenso patrimônio e poderio econômico, social e político, que o inseriram entre o rol dos homens mais ricos da região (ALMEIDA, 2010).

Casando-se com a filha mais velha de João Pinto, Francisca Pinta de Oliveira, Antônio Duarte auferiu ainda mais privilégio e notoriedade por pertencer a uma das parentelas mais distintas e afortunadas da região. Para os Pinto Alves a inserção de um genro com as posses e

\footnotetext{
${ }^{26}$ ACSM, Livro de Notas, 36, $1^{\circ}$ oficio, número 652, 01/09/1731.

${ }^{27}$ ACSM, Livro de Notas $91,1^{\circ}$ ofício, número 1280, 27/08/1773.

${ }^{28}$ ACSM, Livro de Notas, 36, $1^{\circ}$ oficio, número 652, 01/09/1731 e ACSM, Livro de Notas $91,1^{\circ}$ ofício, número $1280,27 / 08 / 1773$.

${ }^{29}$ Ibidem.

${ }^{30}$ ACSM, Livro de Notas, 36, $1^{\circ}$ oficio, número 652, 01/09/1731.

${ }^{31}$ ACSM, Inventário post-mortem de Francisca Pinta de Oliveira, $1^{\text {o }}$ ofício, códice 10, auto 360, 1754.
} 
o cabedal do lusitano foram determinantes para a manutenção e a ampliação do prestígio e honraria que possuíram.

Com o falecimento da esposa, em 1754, Antônio Duarte dispôs de uma fortuna avaliada em 30:249\$160 réis (8.508,905 libras), entre lavras de minerar, 47 escravizados, entre outros bens ${ }^{32}$. Deste montante, 5:041\$525 réis $(1.418,150$ libras) foram destinados à terça da consorte, integralmente transmitida em testamento ao marido "pra dele gozar como sua sem que fosse obrigado a dar contas" ${ }^{\prime 3}$. A terça poderia ser delegada pelo testador a quem lhe aprouvesse e foi, em sua maioria, despendida em "missas e sufrágios para o bem da alma" (CHAMON, 1993, p. 60). No entanto, em alguns casos, os testadores instituíam um único indivíduo que recebia a quantia ou a transferia aos cônjuges, como fez Francisca Pinta.

Dos sete filhos do casal todos legaram da herança materna 1:440\$436 réis $(405,185$ libras), quitados de créditos que o genitor Antônio Duarte contou receber na região, em alguns objetos, escravizados e o fragmento pertencente a cada herdeiro da lavra de minerar do Morro da Passagem ${ }^{34}$. Como exposto, ao inserir créditos no montante em que cada herdeiro auferia, o inventariante prolongava a execução dos autos do processo e adiava a obtenção do legado. Como ressaltou Sheila Faria:

$\mathrm{Na}$ realidade, entretanto, estamos lidando com intenções, e não com fatos. Muito provavelmente, durante muito tempo os herdeiros, em particular o viúvo (a), manteriam os bens. Contas de testamento e inventário arrastavamse por anos, com demandas, processos, cobranças de dívidas, etc., contribuindo para a morosidade. A distribuição dos bens nos inventários estabelecia, em geral, para a "terça", dívidas de outros para com os defuntos. Cobrar essas dívidas não era tarefa fácil (FARIA, 1998, p. 275).

Nos autos do processo, a divisão dos bens e a legítima materna foi elaborada conforme as normas vigentes de partilha igualitária, ainda que sem o embolso imediato pelos descendentes, como de costume. Em 1771, os herdeiros ainda aguardavam a consecução da partilha, recebendo o genitor uma notificação do juízo dos órfãos exigindo a efetivação do inventário da esposa, com pena de "privação do usufruto e da administração da legítima dos filhos"35.

Delongar o cumprimento dos autos do processo foi habitual entre os indivíduos nesse período, principalmente quando um dos cônjuges se encontrasse vivo, já que foi imprescindível manter o patrimônio nas mãos dos familiares, em específico do viúvo (a), que

\footnotetext{
${ }^{32}$ ACSM, Inventário post-mortem de Francisca Pinta de Oliveira, $1^{\circ}$ ofício, códice 10, auto 360, 1754.

${ }^{33}$ Testamento de Francisca Pinta de Oliveira. In: ACSM, Inventário post-mortem de Francisca Pinta de Oliveira, $1^{\circ}$ ofício, códice 10 , auto $360,1754$.

${ }^{34}$ ACSM, Inventário post-mortem de Francisca Pinta de Oliveira, $1^{\circ}$ ofício, códice 10, auto 360, 1754.

${ }^{35}$ ACSM, Inventário post-mortem de Francisca Pinta de Oliveira, $1^{\circ}$ ofício, códice 10, auto 360, 1754.
} 
doava, muitas vezes, bens aos filhos para evitar o fracionamento do patrimônio por intermédio da divisão legal. Possivelmente, Antônio Duarte postergou o quanto pôde a inventariação dos bens da esposa, evitando a desagregação das posses com a exigência de destinar a legítima materna aos herdeiros, o que resultou em uma nova elaboração do inventário de Francisca Pinta, em 1772, com Antônio como inventariante e o filho mais velho do casal João Duarte Pinto como tutor dos órfãos ${ }^{36}$.

Ao que consta, no ano de 1772, o genitor Antônio Duarte faleceu, protelando que três dos herdeiros recebessem a legítima materna: o Padre Antônio Duarte Pinto e os dois menores de 25 anos, Manoel Duarte Pinto e Felipe Benício Duarte. Durante os 18 anos, desde a morte de Francisca Pinta, ao que parece, o lusitano usufruiu dos bens que pertenceram a estes herdeiros, administrando-os e gerindo-os, e concedendo aos demais filhos alguma doação ou herança. Aparentemente, neste período e como inferiu a descrição, a partilha formal diferenciava-se da partilha informal, cabendo ao genitor, se ainda vivo, decidir como a herança era distribuída.

Antônio Duarte, legando aos demais filhos o que lhes pertenceram na legítima ou em doações - possivelmente por estarem casados e serem detentores de cabedais e ofícios restava aos demais filhos mencionados, solteiros, menores de idade e provavelmente regidos pelas ordens paternas, aguardar as deliberações do genitor quanto a liberação da legítima materna. Na prática, a lei de igualdade hereditária não se aplicava com a eficiência e a rapidez que se esperava nem com a paridade exigida.

Com o falecimento do genitor, os três descendentes supracitados recorreram ao juízo dos órfãos solicitando que o patrimônio mantido pelo genitor ao longo dos anos fosse penhorado em praça pública para que pudessem embolsar o valor correspondente da herança $^{37}$. Conquanto Manoel e Felipe possivelmente residissem com o pai durante os anos supracitados e desfrutando dos bens, sentiram-se lesados em relação aos irmãos, o que os fez exigir que os objetos vendidos pelo genitor fossem novamente inseridos no rol do patrimônio para renegociação em praça. Sem acesso ao inventário de Antônio Duarte, sabemos pelos autos do inventário do filho Felipe Benício que, nos anos de 1777, o pagamento da legítima materna era mantida como litigiosa ${ }^{38}$, o que impediu, provavelmente, que esses indivíduos auferissem o cabedal material fundamental para que fossem inseridos no rol dos principais senhores de terras e escravizados da região.

\footnotetext{
${ }^{36}$ ACSM, Inventário post-mortem de Francisca Pinta de Oliveira, $1^{\text {o }}$ ofício, códice 21, auto 591, 1772.

${ }^{37}$ Ibidem.

${ }^{38}$ ACSM, Inventário post-mortem de Felipe Benício Duarte, $1^{\circ}$ ofício, códice 75, auto 1585, 1777.
} 
Felipe Benício, a título de exemplo, faleceu aos 28 anos, solteiro e detentor unicamente de trajes pessoais, três escravizados (avaliados em 375\$000 réis - 105,485 libras) e dois alqueires de milho plantado no valor total de $432 \$ 400$ réis $(121,631 \text { libras })^{39}$. Impedido de obter a legítima, o filho de Antônio Duarte, embora herdeiro de um dos homens mais ricos e poderosos da região de Mariana, viu-se impossibilitado de manter e ampliar a riqueza social e econômica dos familiares, falecendo detentor de um montante irrisório. O dote, as doações realizadas anteriormente ao falecimento dos genitores, as legítimas paternas e maternas, ao que nos consta, auxiliaram, sobremaneira, a manutenção e a ampliação destes indivíduos como senhores de posses da região, conferindo-lhes poderio material e imaterial.

João Duarte Pinto, igualmente filho de Antônio e Francisca Pinta, não obstante também tenha falecido com uma fortuna reduzida ${ }^{40}$, angariou, ao longo dos anos, distinção e poder ao integrar o rol de vereadores da câmara de Mariana, em 1778 (CHAVES; PINTO, MAGALHÃES, 2008). João Duarte, ciente das regalias, privilégios e honrarias que o cargo oferecia, esforçou-se para manter o cargo de vereador a todo custo, subornando o desembargador e juiz de fora, o que acarretou em sua prisão e sua intercessão junto à Coroa ${ }^{41}$.

Embora detentor de onze escravizados avaliados em 1:250\$000 réis (404,947 libras), João Duarte possuía apenas uma fazenda, da qual metade pertencia a seu irmão, o Padre Antônio Duarte Pinto e outra parte negociada com o sobrinho, o Padre João Ferreira Almada, que, no fim de sua vida, estava penhorada no valor de $250 \$ 000$ réis $(80,989 \text { libras })^{42}$. Como referido, alguns indivíduos, como João Duarte, embora pertencentes a parentelas detentoras de fortuna e distinção, não adquiriram ou mantiveram o cabedal material dos ascendentes, legando aos filhos um montante muito inferior ao que auferiram de suas heranças.

O inventário de João Duarte expõe a continuidade, nos fins do século XVIII, dos mesmos preceitos do início, com o genitor doando dote às filhas casadoiras e patrimônio aos filhos eclesiásticos. De seus oito filhos com Sebastiana Maria de Jesus, cinco filhas receberam um escravizado como dote ao se casarem, dois dos filhos obtiveram o patrimônio para iniciar a carreira eclesiástica na posse de um escravizado cada um, e uma das filhas se manteve solteira por toda a vida, possivelmente para zelar pelos genitores na velhice ${ }^{43}$.

\footnotetext{
${ }^{39}$ ACSM, Inventário post-mortem de Felipe Benício Duarte, $1^{\circ}$ ofício, códice 75, auto 1585, 1777.

${ }^{40}$ Monte-mor: 2:126\$310 réis (688,835 libras). ACSM, Inventário post-mortem de João Duarte Pinto, $1^{\circ}$ ofício, códice 94, auto 1964, 1817.

${ }^{41}$ AHU, cx. 114, doc. 9, 13 de janeiro de 1779.

${ }^{42}$ ACSM, Inventário post-mortem de João Duarte Pinto, $1^{\circ}$ ofício, códice 94, auto 1964, 1817.

${ }^{43}$ ACSM, Inventário post-mortem de João Duarte Pinto, $1^{\circ}$ ofício, códice 94, auto 1964, 1817.
} 
Entre os genros de Antônio Duarte, João Ferreira Almada casado que foi com Mariana Clara Rosa de Oliveira, em $1759^{44}$, esteve entre o rol dos grandes mineradores e homens mais ricos da região de Minas (ALMEIDA, 2010). Em seu inventário catalogado em 1769, entre seus bens estiveram arrolados dois créditos significativos; em um deles, o sogro Antônio Duarte e o cunhado Antônio Duarte Pinto deviam a João Ferreira 6:000\$000 réis (1.687,763 libras) por negociação de alguns de seus bens, e o outro em que os sócios Antônio dos Santos Aguiar e José Ribeiro Fortes necessitavam liquidar de 4:937\$625 réis (1.388,924 libras) de uma transação realizada em $1752^{45}$. As duas dívidas somadas se aproximaram do valor integral do monte-mor de João Ferreira, avaliado em 13:103\$875 réis $(3.686,040 \text { libras })^{46}$ constituindo-se como o principal patrimônio do lusitano.

Em seu testamento, igualmente elaborado em 1769, João Ferreira informou que entre os bens declarados no monte do casal, de raiz, semoventes, móveis e outros, foi vendido a sua meação ao sogro Sargento-Mor Antônio Duarte e ao cunhado Reverendo Antônio Duarte Pinto pelo montante de 15 mil cruzados (6:000\$000 réis - 1.687,763 libras), pagos 300\$000 réis $\left(84,388\right.$ libras) no fim de cada ano até a completude do crédito ${ }^{47}$.

Possivelmente, a estratégia de vender sua meação a um familiar tinha como intuito evitar o fracionamento dos bens e o empobrecimento do cônjuge e dos filhos com pagamento de dívidas e divisão igualitária do patrimônio. Assim, durante a suposta venda de todos os seus móveis, cativos e posses de terras, apenas o restante de seu patrimônio, entre roupas, objetos pessoais e os créditos permaneceram como líquido para inventariação, reduzindo o monte-mor para 6:579\$780 réis (1.850,852 libras) e a legítima dos herdeiros para 1:096\$630 réis $(308,475 \text { libras })^{48}$.

Ao nomear em testamento a esposa Mariana Rosa como a única tutora dos bens do casal e dos filhos, João Ferreira transmitiu à cônjuge uma série de responsabilidades que perpassavam desde a administração do patrimônio à regência do destino dos descendentes. Podemos considerar, desta forma, que a comercialização da meação constituía realmente uma estratégia para manter os principais bens nas mãos dos herdeiros, que, acrescidos de outros

\footnotetext{
${ }^{44}$ AEAM, Processo Matrimonial, registro 5623, armário 05, pasta 463, 1759.

${ }^{45}$ ACSM, Inventário post-mortem João Ferreira Almada, $1^{\circ}$ ofício, códice 80, auto 1696, 1769.

${ }^{46}$ Ibidem.

${ }^{47}$ Testamento de João Ferreira Almada. In: ACSM, Inventário post-mortem João Ferreira Almada, $1^{\circ}$ ofício, códice 80, auto 1696, 1769.

${ }^{48}$ ACSM, Inventário post-mortem João Ferreira Almada, $1^{\circ}$ ofício, códice 80, auto 1696, 1769.
} 
recursos adquiridos por Mariana Rosa em sua sociedade com o genitor, fizeram desta viúva chefe de domicílio ${ }^{49}$.

Embora esses preceitos sejam suposições, observamos que existiu na execução da venda da meação um mecanismo (possível "venda fantástica”) para que as posses de terras e escravizados de João Ferreira, fonte de riqueza e distinção, não se dissipassem entre dívidas e execuções sucessórias. Os mecanismos aplicados pelo lusitano não foram aleatórios e implicaram diretamente na preservação dos recursos e do padrão familiar, visto que, falecendo quando os filhos ainda eram mancebos, foi imprescindível dispor aos herdeiros condições econômicas e sociais satisfatórias para que pudessem auferir um futuro promissor. Desta forma, detectamos outra estratégia empregada pelos indivíduos a fim de burlar as leis portuguesas de igualdade hereditária, dificultando, ademais, o fracionamento do patrimônio e a redução do poderio econômico e social.

Consideramos igualmente que essas transações se conectaram com o que Giovanni Levi intitulou de "solidariedade parental" em que os indivíduos de uma mesma família, mesmo que não corresidentes, se amparavam em momentos de insegurança econômica e social:

Um segundo aspecto é relativo aos problemas ligados à relação entre famílias e parentes não corresidentes na gestão conjunta dos patrimônios comuns (ou individuais, quando gerenciados no quadro de ampla reciprocidade generalizadas, mesmo no caso de herança divisível). A própria profissão do chefe de família de cada núcleo deve ser vista neste quadro: ela não define de fato uma estratégia econômica em si concluída; ao contrário, frequentemente, as frentes parentais exercem as próprias práticas de equilíbrio perante o risco e a incerteza, diferenciando os setores de atividade entre parentes não corresidentes, mas amplamente ligados em sistemas de solidariedades. Pensamos, por exemplo, nas relações entre famílias intimamente ligadas de irmãos ou pais/filhos nas quais são praticadas atividades diversificadas e independentes, porém todas confluentes para a formação de uma renda comum: trabalho manufatureiro/ agricultura ou propriedade/ emigração ou colônia parziarial propriedade (LEVI, 2015, p. $16)$.

Como Levi, pressupomos que a "venda" de seus maiores recursos ao sogro e ao genro, salvo a questão de preservação patrimonial, esteve coligada igualmente à solidariedade parental, por meio da qual os familiares auxiliavam a viúva a gerir os recursos em momento de crise (como no falecimento de João Ferreira). O patrimônio, desta forma, se mantinha nas mãos dos familiares, sem fragmentação, administrado pela parentela e pela viúva, assinalada

\footnotetext{
${ }^{49}$ Antônio Duarte era sócio com a filha nos seguintes bens: 39 escravizados, um sítio com moinho, paiol e águas minerais; ferramentas para extrair ouro; senzala e casas de camaradas; outro sítio com terras e águas minerais com milho, feijão e arroz colhidos; outro sítio com casas de vivenda, moinho, olaria, senzalas e terras com águas minerais e 16 alqueires de milho. In: ACSM, Inventário post-mortem de Francisca Pinta Oliveira, $1^{\circ}$ ofício, códice 22, auto 591, 1772.
} 
no inventário do genitor como sua sócia em diferentes bens, incluindo os "negociados" na transação. Provavelmente, ao longo dos anos, Antônio Duarte e o filho apoiaram Mariana Rosa na gestão dos bens legados pelo cônjuge, ampliando-os e mantendo-os para sustento dos descendentes, preservando as benesses e privilégios adquiridos.

Ao que parece, inseridos em uma ótica de "casa", como descrito, além de trilhar os mesmos parâmetros comportamentais, essas famílias favoreceram a manutenção econômica e social de todos os indivíduos em amplas redes de solidariedade. Segundo Levi:

Fica claro que as relações significativas excedem o parentesco; redes de clientela e proteção, redes de amizade e reciprocidade, redes de crédito e troca são elementos essenciais em jogo e frequentemente sobrepostos de maneira múltipla com os laços de consanguinidade e afinidade (LEVI, 2015, p. 18).

Redes de amizade, apadrinhamentos, sociedades, redes de créditos, entre outros vínculos, agruparam esses indivíduos em complexas teias de proteção social e econômica, no intuito de zelar pela riqueza e prestígio do círculo.

Outro importante indivíduo da rede familiar do Pinto Alves, como descrito, foi o português Domingos Coelho, que desembarcou em terras brasileiras em $1741^{50}$, contraindo esponsais com a filha de Antônio Duarte, Dona Feliciana Isabel Maria de Oliveira no ano de $1759^{51}$. Licenciado em medicina, o lusitano obteve comendas, mercês e ofícios, foi Familiar do Santo Ofício, em $1756^{52}$, e esteve na lista dos homens mais ricos das Minas (ALMEIDA, 2010), como grande minerador e agricultor da região.

Genitor de dez filhos com Feliciana Isabel, o lusitano, ao inventariar os bens da esposa no ano de 1782 , legou como herança materna o valor de $975 \$ 146$ réis $\left(274,302\right.$ libras ${ }^{53}$ a cada descendente, sem maiores contendas ou impasses. Detentor de uma fortuna avaliada em 20:302\$925 réis $(5.711,090$ libras) entre terras, lavras minerais, engenhos de cana e 101 escravizados (no valor total de 8:783\$000 réis $-2.470,604$ libras ${ }^{54}$ ), o português angariou uma trajetória de sucesso na região entre riquezas materiais e privilégios sociais que favoreceram o êxito dos filhos.

Embora sem litígios aparentes, ao que parece, de acordo com o testamento realizado pelo filho Licenciado Joaquim Coelho Oliveira Duarte, em 1833, a legítima paterna de Domingos Coelho, no ano em destaque, não foi distribuída entre todos os herdeiros, permanecendo sua parte nas mãos de três sobrinhos, filhos de seu irmão Capitão-Mor José

\footnotetext{
${ }^{50}$ ANTT, Habilitações do Santo Ofício, maço 136, doc. 255, 1755.

${ }^{51}$ AEAM, Processo matrimonial de Domingos Coelho, 1759, registro 3674, armário 2, pasta 40.

${ }^{52}$ ANTT, Habilitações do Santo Ofício, Letra D, maço 43, doc. 728, 1755.

${ }^{53}$ ACSM, Inventário post-mortem de Feliciana Isabel Maria de Oliveira, $1^{\circ}$ ofício, códice 74, auto 1569, 1782.

${ }^{54}$ Ibidem.
} 
Coelho Oliveira Duarte: José Coelho Duarte Badaró, Francisco Coelho Duarte Badaró e Feliciano Coelho Duarte ${ }^{55}$.

Ao que indica o documento, o irmão de Joaquim Coelho, José Coelho, possivelmente como inventariante ou testamenteiro dos bens do genitor, comprou a principal fazenda legada pelo pai dos demais irmãos, dispondo-se a pagar, ao longo dos anos, o valor correspondente aos herdeiros da legítima, o que não ocorreu, já que, em 1833, os filhos de José, em posse das terras, foram obrigados, a restituir o montante aos sucessores de Domingos. Senhor de uma unidade açucareira, como descrito no inventário do cônjuge, possivelmente Domingos Coelho certificou-se de manter nas mãos de um único herdeiro a fabricação do açúcar. Como destacou Sheila Faria, "era muito importante que todo o conjunto que fazia funcionar um engenho estivesse integralmente nas mãos de uma só pessoa” (FARIA, 1998, p. 262).

Conquanto não tenhamos acesso ao inventário de Domingos Coelho e de José Coelho, os dados apresentados corroboram uma prática por vezes habitual entre as famílias, como a descrita anteriormente, em que um dos herdeiros comprava dos irmãos parte da herança referente à posse de terra, para que esta não se fragmentasse, mantendo-a em família e transmitindo-a aos descendentes, muitas vezes sem que o pagamento da dívida fosse quitado. Com um suposto acordo entre as partes e através de trajetórias distintas, os herdeiros permitiam que um dos irmãos administrasse e mantivesse a principal posse dos genitores intacta, sem fracionamentos, conservando-a na família ao longo dos anos, preservando o prestígio e status que os grandes senhores de terras e escravizados logravam e que, consequentemente, difundiam aos demais descendentes.

Em meados do século XVIII, a despeito do privilégio e das benesses que o renome familiar poderia propagar, a obtenção de novas posses de terras e escravizados foi determinante para a manutenção e a prosperidade material desses indivíduos, o que exigiu, que os três filhos de Antônio Duarte instituíssem uma contenda judicial.

Na quarta geração, entre fins do século XVIII e início do XIX, sob a égide do triunfo familiar, com indivíduos influentes, titulares de poderio econômico e político, os indivíduos se resignaram facilmente diante das desigualdades sucessórias ou da má distribuição da partilha.

Estabelecendo alianças e redes de amizade, por intermédio dos matrimônios, a parentela dos Pinto Alves preferencialmente casou suas filhas com portugueses afortunados e indivíduos distintos, designando os filhos a seguirem carreira eclesiástica ou militar, ou

\footnotetext{
${ }^{55}$ ACSM, Inventário post-mortem de Joaquim Coelho Oliveira Duarte, $2^{\circ}$ ofício, códice 46, auto 1043, 1833.
} 
unindo-os com moças de famílias igualmente relevantes na região. Os casamentos exogâmicos foram primordiais nas primeiras gerações, possivelmente ampliando as teias de relações sociais, econômicas e políticas, reduzindo-se a partir da quinta geração, em que foram privilegiados os matrimônios endogâmicos e consanguíneos, em que os primos se uniam, provavelmente, no intuito de manter o patrimônio e benesses do grupo familiar ${ }^{56}$.

Deste modo, parece-nos evidente que essa parentela e seus indivíduos empregaram propositadamente estratégias e métodos a fim de burlar as normas igualitárias de herança, evitando o fracionamento das propriedades e a dissolução dos bens em quitação de dívidas; ora vendendo supostamente a meação da herança, ora postergando o pagamento das legítimas, no intuito patente de preservar todas as regalias e riquezas auferidas ao longo dos anos. Dentre todas as famílias de Guarapiranga pesquisadas, os Pinto Alves foram o mais extenso tronco familiar da análise, detendo cargos, ofícios, prestígio e renome na região de Mariana até fins do século XIX.

Observamos que as normas e leis se debateram com a prática vigente. Os interesses sociais, políticos e econômicos a todo tempo foram de encontro às leis impostas por um Reino distante, que mal conheceu a realidade costumeira de pessoas que se empenharam a todo custo para enriquecerem e se diferenciarem da plebe pobre e dos cativos "desalmados"; de pessoas que se habituaram a escravizar e a vilipendiar a vida alheia a fim de se manter no topo da hierarquia, em sua maioria, despóticos, mandatários e presunçosos; que privilegiaram alguns dos filhos em nome da bonança, do status, da posição; que, com esforço, se mantiveram senhores de terras e escravizados por intermédio de estratégias e métodos que burlavam as leis. Seus mecanismos não foram aleatórios nem ingênuos e seguiram os parâmetros de uma sociedade pautada pelos preceitos supersticiosos da religião, da hierarquização e da escravidão.

\section{Conclusão}

O trabalho analisou a freguesia de Guarapiranga, na região de Mariana, entre 1715 a 1820, procurando identificar as principais estratégias empregadas pelos grupos e familiares fixados na freguesia quando da realização dos matrimônios e da concessão de heranças. Para tanto, examinamos uma família em especial residentes no período na localidade, os Pinto Alves.

${ }^{56}$ ACSM, Inventários post-mortem entre 1715 a 1880. 
Estamos diante de uma família, como outras do além-mar, que, almejando galgar regalias e privilégios no seio social em que se inseriram, empregaram mediante os casamentos dos filhos e, principalmente das filhas, métodos e estratégias singulares para auferirem poder e patrimônio. Foram, em sua maioria, senhores de terras e escravizados que ampliaram suas redes de relações sociais, econômicas e políticas do ultramar ao reino, esforçando-se para conservar aos descendentes a autoridade e riqueza que adquiriram, por vezes, burlando as leis portuguesas e instituindo mecanismos particulares, como descrito ao longo do trabalho.

Em relação às heranças e sucessões localizamos para a região a perpetuação de estratégias de manutenção do patrimônio, por intermédio das chamadas "vendas fantásticas", identificada em outros pontos em Minas Gerais e em toda a Colônia, em que os indivíduos realizavam transações fictícias sem que fizessem a transferência de fato da posse dos bens negociados. Empregavam, com o mesmo fim, a venda da meação do espólio aos genros, cunhados, filhos e esposas no intuito de evitar o fracionamento dos bens, empobrecimento dos familiares com pagamentos de dívidas e divisão igualitária. Esses recursos foram empregados igualmente por outros indivíduos e famílias da freguesia de Guarapiranga e demais regiões, manejando os métodos utilizados conforme a necessidade e a riqueza adquirida. Litígios arrastados ao longo dos anos igualmente impediram que dívidas e divisão igualitária reduzissem ou fragmentasse o patrimônio legado.

No que diz respeito à partilha, reiteradamente foi possível discernir que a formal se diferenciara da informal, cabendo ao genitor ainda vivo decidir como os bens seriam distribuídos. Por vezes, a morosidade do embolso das legítimas, a título de exemplo, gerava litígios entre os familiares, impedindo o enriquecimento de algum dos herdeiros, principalmente os que viveram ao redor do domicílio paterno sob a égide do patriarca.

Esperamos que este trabalho sobre herança e sucessão na freguesia de Guarapiranga entre 1715 a 1820 contribua em alguma medida para melhor compreendermos a diversidade das estratégias utilizadas pelos grupos de elite para se preservarem nesta condição na dinâmica da sociedade mineira no período analisado.

\section{Referências bibliográficas}

ALMEIDA, Carla Maria Carvalho de. Ricos e Pobres em Minas Gerais: produção e hierarquização social no mundo colonial, 1750-1822. Belo Horizonte, MG: Argvmentvm, 2010.

ALMEIDA, Carla M.C. As vendas fantásticas dos homens ricos das Minas: estratégias de preservação do patrimônio familiar no século XVIII. In: LIBBY, Douglas Cole; MENESES, 
José Newton Coelho; FURTADO, Júnia Ferreira; FRANK, Zephyr, L.. (Org.). História da família no Brasil (séculos XVIII, XIX e XX): novas análises e perspectivas. 1ed. Belo Horizonte: Fino Traço, 2015.

AMORIM, Maria Norberta; DURÃES, Margarida \& FERREIRA, Antero. Bases de dados genealógicas e história da família em Portugal: análises comparativas (do antigo regime à contemporaneidade). In: La historia de la família en la Península Ibérica. Balance y perspectivas. Homenaje a Peter Laslett. Albacete: UCLM, 2003.

ANDRADE, Mateus Rezende de. Compadrio e Família em zona de fronteira agrícola: as redes sociais da elite escravista, freguesia de Guarapiranga (1760 - 1850). Dissertação apresentada ao programa de Pós- Graduação em História da Faculdade de Filosofia e Ciências Humanas da UFMG. Belo Horizonte, 2014.

BRETTELL, Caroline. Homens que partem, mulheres que esperam: consequências da emigração numa freguesia minhota. Lisboa: Dom Quixote, 1991.

CALDEIRA, João Luís Picão. O Morgadio e a Expansão no Brasil. Lisboa: Ver Curiosidade, 2007.

CARRARA, Ângelo Alves. Minas e Currais: produção rural e mercado interno em Minas Gerais 1674-1807. Juiz de Fora: Ed. UFJF, 2007.

CHAMON, Carla Simone. O Bem da Alma: a terça e a tercinha do defunto nos inventários do século XVIII da Comarca do Rio das Velhas. Varia História, Belo Horizonte, nº 12 , dezembro de 1993.

CHAVES, Cláudia Maria das Graças; PIRES, Maria do Carmo; MAGALHÃES, Sônia Maria (orgs.). Casa de Vereança de Mariana: 300 anos de História da Câmara Municipal. Ouro Preto: Editora UFOP, 2008.

DURÃES, Margarida. Filhos e Enteados: práticas sucessórias e hereditárias no mundo rural (Braga, séculos XVIII - XIX). Cadernos do Nordeste, 15 (1-2), 2001.

FARIA, Sheila de Castro. A Colônia em Movimento: Fortuna e Família no Cotidiano Colonial. Rio de Janeiro: Nova Fronteira, 1998.

FIGUEIREDO, Luciano Raposo de Almeida; CAMPOS, Maria Verônica (coord.). Códice Costa Matoso. Coleção das notícias dos primeiros descobrimentos das minas na América que fez o doutor Caetano da Costa Matoso sendo ouvidor-geral das do Ouro Preto, de que tomo posse em fevereiro de 1749 \& vários papéis. Belo Horizonte: Fundação João Pinheiro, 1999.

FRAGOSO, João. A formação da economia colonial no Rio de Janeiro e de sua primeira elite senhorial (séculos XVI e XVII). In: FRAGOSO, João; BICALHO, Maria Fernanda e GÔUVEA, Maria de Fátima (orgs). O Antigo Regime nos Trópicos: a dinâmica imperial portuguesa (séculos XVI - XVIII). Rio de Janeiro: Civilização Brasileira, 2001.

LEVI, Giovanni. Reflexões sobre família e parentela. In: VENDRAME, Maíra Ines; KARSBURG, Beatriz Weber e FARINATTI, Luis Augusto (orgs). Micro-história, trajetórias e imigração. São Leopoldo: Oikos, 2015.

LOPES, Luiz Fernando Rodrigues. Vigilância, Distinção e Honra: os familiares do Santo Ofício na Freguesia de Nossa Senhora da Conceição de Guarapiranga, Minas Gerais, 1753 1801. 2012. Dissertação (Mestrado em História) - Pós- Graduação em História, Universidade Federal de Juiz de Fora, Juiz de Fora, 2012.

MAGALHÃES, Joaquim Romero. O Algarve Econômico: 1600 - 1773. Lisboa: Estampa, 1988.

MONTEIRO, Nuno Gonçalo. Casa e linhagem: o vocabulário aristocrático em Portugal nos séculos XVII e XVIII. Penélope. Fazer e desfazer a História, nº 12, 1993.

MOURA, Margarida. Os herdeiros da terra: parentesco e herança numa área rural. São Paulo: Hucitec, 1978.

PEDROZA, Manoela. Estratégias de reprodução social de famílias senhoriais cariocas e minhotas. Análise Social, vol. XLV (194), 2010 
ROWLAND, Robert. População, família, sociedade: Portugal, séculos XIX-XX. Oeiras: Celta, 1997. 